\title{
Sustainable Production of Reduced Phosphorus Compounds: Mechanochemical Hydride Phosphorylation Using Condensed Phosphates as a Route to Phosphite
}

\author{
Feng Zhai, ${ }^{\dagger, \ddagger}$ Tiansi Xin, ${ }^{\dagger, \ddagger}$ Michael B. Geeson, ${ }^{\dagger}$ and Christopher C. Cummins ${ }^{*}, \dagger$ \\ $\dagger$ Department of Chemistry, Massachusetts Institute of Technology, Cambridge, MA 02139, USA \\ $\ddagger$ These authors contributed equally to this work \\ Received November 8, 2021; E-mail: ccummins@mit.edu
}

\begin{abstract}
Phosphorus removal and recovery technologies have been implemented to tackle the anthropogenic eutrophication caused by phosphate runoff into waterways. In pursuit of a better utilization of the phosphates recovered from waste water treatment, we herein report that condensed phosphates can be employed to phosphorylate hydride reagents under solvent-free mechanochemical conditions to furnish phosphite $\left(\mathrm{HPO}_{3}{ }^{2-}\right)$, a versatile chemical with phosphorus in the +3 oxidation state. Hydride phosphorylation, as a two-electron one-proton reduction of a main group element oxide, constitutes a direct parallel with $\mathrm{CO}_{2}$ reduction to formate. Using potassium hydride as the hydride source, sodium trimetaphosphate $\left(\mathrm{Na}_{3} \mathrm{P}_{3} \mathrm{O}_{9}\right)$, triphosphate $\left(\mathrm{Na}_{5} \mathrm{P}_{3} \mathrm{O}_{10}\right)$, and pyrophosphate $\left(\mathrm{Na}_{4} \mathrm{P}_{2} \mathrm{O}_{7}\right)$ engendered phosphite in 44,58 , and $44 \%$ yields based on total $P$ content, respectively, under their optimal conditions. Formation of overreduced products including hypophosphite $\left(\mathrm{H}_{2} \mathrm{PO}_{2}{ }^{-}\right)$was identified as a competing process, and mechanistic investigation revealed that hydride attack on in situ generated phosphorylated phosphite species is a potent pathway for overreduction. The phosphite generated from our method could be easily isolated in the form of barium phosphite, a useful intermediate for production of phosphorous acid. This method circumvents the need to pass through white phosphorus $\left(\mathrm{P}_{4}\right)$ as a high energy intermediate and mitigates involvement of environmentally hazardous chemicals. A bioproduced polyphosphate from baker's yeast was demonstrated to be a viable starting material for the production of phosphite. This example demonstrates the possibility of accessing reduced phosphorus compounds in a more sustainable manner, and more importantly, closing the modern phosphorus cycle.
\end{abstract}

Phosphorous acid $\left(\mathrm{H}_{3} \mathrm{PO}_{3}\right)$ and its conjugate base, phosphite $\left(\mathrm{HPO}_{3}{ }^{2-}\right)$, have found applications as reducing agents, as the starting material for preparing basic lead phosphite, ${ }^{1}$ a stabilizer for chlorine-containing plastics, as cathode materials for lithium- and sodium-ion batteries, ${ }^{2-4}$ as well as the starting material for other commercially important reduced phosphorus compounds, such as glyphosate. ${ }^{5}$ Phosphite and related $H$-phosphonate esters are a family of key intermediates to organophosphorus compounds via elaboration of the $\mathrm{P}-\mathrm{H}$ function into $\mathrm{P}-\mathrm{C}$ bonds. ${ }^{6-12}$ Recent advances in biotechnology have also cleared out a path for phosphite to act as an environmentally friendly herbicide, biostimulant, and biocide in modern agriculture owing to its minimal toxicity to humans and animals, biodegradability in soil, and

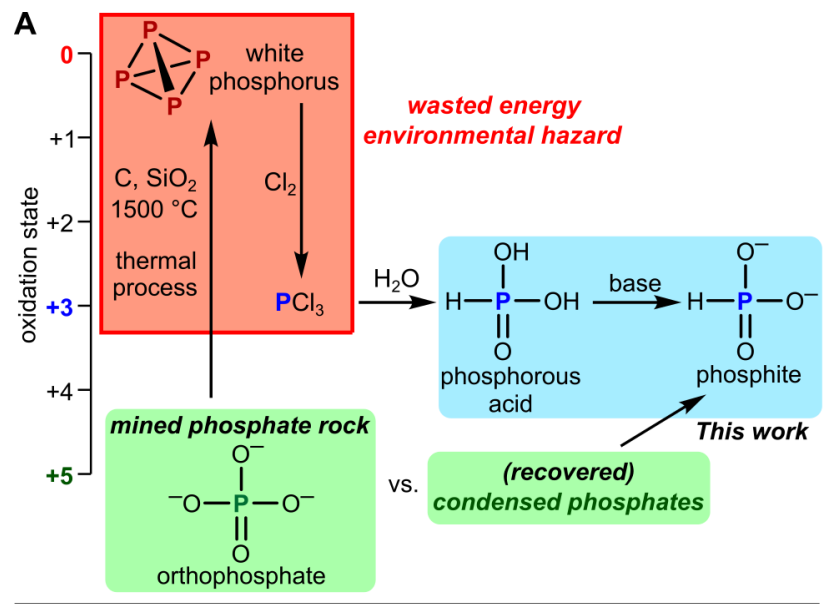

B condensed phosphates
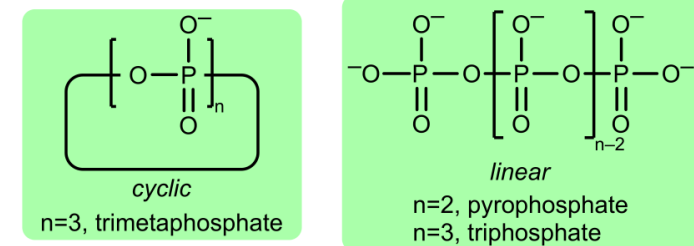

$\mathrm{n}=2$, pyrophosphate $n=3$, triphosphate

C mechanochemical hydride phosphorylation (this work)

$$
1 / \mathrm{n}\left[\mathrm{P}^{\vee} \mathrm{O}_{3}\right]_{n}{ }^{\mathrm{n}-}+\mathrm{H}^{-} \stackrel{8}{\longrightarrow}\left[\mathrm{HP}^{\mathrm{III}} \mathrm{O}_{3}\right]^{2-}
$$

Figure 1. (A) Thermal process for manufacture of phosphorous acid and phosphite (red) versus the envisioned new process to produce phosphite (cyan) from phosphate inputs (green) without traversing the lower oxidation states; (B) structures of cyclic and linear condensed phosphates; (C) reaction design of mechanochemical phosphorylation of hydrides using condensed phosphates (this work).

inability to trigger eutrophication of natural water bodies through agricultural runoff. ${ }^{13}$ The development of transgenic crops that metabolize phosphite rather than phosphate has allowed phosphite to serve as both fertilizer and herbicide. ${ }^{14,15}$ Additionally, phosphite is thought to have been a potential major nutrient in the pre-oxygenated Archaen oceans. ${ }^{16}$

However, current production of phosphorous acid relies on an energy-intensive process known as the thermal process in which the phosphorus in phosphate rock is first reduced at $1500{ }^{\circ} \mathrm{C}$ to $\mathrm{P}(0)$ (white phosphorus, $\mathrm{P}_{4}$ ), followed by oxidation back to $\mathrm{P}(\mathrm{III})$ as $\mathrm{PCl}_{3}$ using chlorine gas. Subsequent 
hydrolysis provides phosphorous acid (Figure 1A). ${ }^{1,17}$ This carbothermal legacy process is very energy intensive and involves substances that are environmentally hazardous. In addition to phosphate rock, the primary source of phosphorus, phosphate recovery from waste streams is becoming an increasingly important method to obtain phosphorus, ${ }^{18}$ as phosphorus is a nonrenewable resource ${ }^{19-21}$ and high concentrations of phosphate in a water body lead to eutrophication. $^{22}$ Among those phosphate recovery methods, one well-established process, known as enhanced biological phosphorus removal (EBPR), utilizes microorganisms to take up phosphate from waste water and store it in intracellular polyphosphate granules. ${ }^{23-25}$ In the "Heatphos Process", polyphosphate can be released from bacteria by heating at $70{ }^{\circ} \mathrm{C}$ for 1 hour. ${ }^{26,27}$ The recovered phosphate can be used as a raw material for the fertilizer industry.

Recently we showed that phosphate is a suitable precursor to chemicals traditionally synthesized from white phosphorus. ${ }^{28-33}$ Building upon these principles, we sought to develop a process for the reduction of recovered phosphate to phosphite, bypassing hazardous white phosphorus and chlorine and minimizing energy waste (Figure 1A). ${ }^{34}$ The envisioned reaction, hydride phosphorylation, can be considered as directly analogous to the canonical two-electron, one-proton reduction of a main-group element oxide: for instance, $\mathrm{CO}_{2}$ reduction to formate. ${ }^{35,36}$

Our curiosity in regard to this topic was piqued by the industrial synthesis of sodium fluorophosphate $\left(\mathrm{Na}_{2} \mathrm{PO}_{3} \mathrm{~F}\right)$, an active ingredient in toothpaste. In a $100 \%$ atom-efficient reaction, sodium trimetaphosphate $\left(\mathrm{Na}_{3} \mathrm{P}_{3} \mathrm{O}_{9}\right)$ and three equivalents of sodium fluoride are heated to $300{ }^{\circ} \mathrm{C}$ resulting in a melt and the formation of $\mathrm{Na}_{2} \mathrm{PO}_{3} \mathrm{~F}:{ }^{37}$

$$
\mathrm{Na}_{3} \mathrm{P}_{3} \mathrm{O}_{9}+3 \mathrm{NaF} \underset{300{ }^{\circ} \mathrm{C}}{\longrightarrow} 3 \mathrm{Na}_{2} \mathrm{PO}_{3} \mathrm{~F}
$$

Sodium trimetaphosphate $\left(\mathrm{Na}_{3} \mathrm{P}_{3} \mathrm{O}_{9}\right)$, readily produced by the dehydration of phosphoric acid with sodium chloride, ${ }^{38}$ is the smallest cyclic phosphate with a $\mathrm{O}: \mathrm{P}$ ratio of three (Figure 1B), identical to that in phosphite. It is therefore an attractive starting material for reduction to produce phosphite. In analogy to the industrial production of $\mathrm{Na}_{2} \mathrm{PO}_{3} \mathrm{~F}$, we hypothesized that the reaction of $\mathrm{Na}_{3} \mathrm{P}_{3} \mathrm{O}_{9}$ with a metal hydride such as sodium hydride $(\mathrm{NaH})$ might give rise to the formation of sodium phosphite $\left(\mathrm{Na}_{2} \mathrm{HPO}_{3}\right)$ :

$$
\mathrm{Na}_{3} \mathrm{P}_{3} \mathrm{O}_{9}+3 \mathrm{NaH} \stackrel{8}{\longrightarrow} 3 \mathrm{Na}_{2} \mathrm{HPO}_{3}
$$

Along the lines of the synthesis of $\mathrm{Na}_{2} \mathrm{PO}_{3} \mathrm{~F}$, our initial strategy involved the thermal reaction between $\mathrm{NaH}$ and $\mathrm{Na}_{3} \mathrm{P}_{3} \mathrm{O}_{9}$ (neat, 3:1 molar ratio) at $300{ }^{\circ} \mathrm{C}$, and we were pleased to observe the formation of the desired phosphite by ${ }^{31} \mathrm{P}$ NMR spectroscopy. However, the presence of unreacted trimetaphosphate as the major phosphorus-containing species at the end of the reaction sequence pointed toward poor conversion. Additionally, the formation of an unusual phosphinophosphate, $\left[\mathrm{H}_{2} \mathrm{P}-\mathrm{OPO}_{3}\right]^{2-}$, which is tentatively assigned based on data from NMR spectroscopy, suggested poor mixing of the solid reagents and high local concentrations of hydride, plausibly leading to overreduction.

In order to overcome this issue, we turned to mechanochemistry. Protocols in which reagents are subjected to intimate mixing and grinding using ball mills have become increasingly popular in recent years, affording reaction products that cannot be obtained using traditional solution-based methods. ${ }^{39-45}$ Additionally, the use of mechanochemistry obviates the need for solvent and can give short reaction times, good scalability, and even opportunities for in situ reaction monitoring. ${ }^{46,47}$ Mechanochemical protocols have been applied to phosphorylate natural and synthetic polymers. ${ }^{48,49}$

Ball-milling reactions were conducted in a shaker mill using steel jars and ball bearings, using commercial hydride sources and thoroughly dehydrated phosphates. All watersoluble phosphorus-containing products were quantified by ${ }^{31} \mathrm{P}$ NMR analysis of an aqueous extract of the solid reaction mixture, and percentage yields and recovery rates of extraction are based on total $\mathrm{P}$ content in the phosphate input. The reaction of $\mathrm{Na}_{3} \mathrm{P}_{3} \mathrm{O}_{9}$ with three equivalents of $\mathrm{NaH}$ $(\mathrm{H}: \mathrm{P}=1: 1)$ led to the formation of the desired product in short reaction times (within $60 \mathrm{~min}$ ) with almost complete consumption of the starting material (Table 1). Other major products included pyrophosphate and orthophosphate. Control experiments confirmed that these phosphate materials did not appear simply by ball-milling $\mathrm{Na}_{3} \mathrm{P}_{3} \mathrm{O}_{9}$ alone under otherwise identical conditions, although $\mathrm{Na}_{3} \mathrm{P}_{3} \mathrm{O}_{9}$ was partially converted to a variety of cyclic and linear phosphates (see SI).
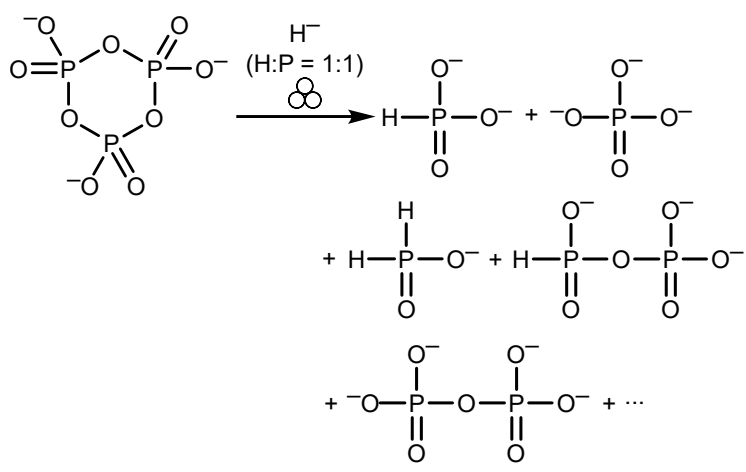

Table 1. Optimization of hydride source ${ }^{a}$

\begin{tabular}{lcc}
\hline hydride & phosphite yield & b,c,d \\
\hline $\mathrm{LiH}$ & 17 & conversion $^{b}(\%)$ \\
$\mathrm{NaH}$ & $10(16)$ & 99 \\
$\mathrm{KH}$ & 23 & 95 \\
$\mathrm{NaBH}_{4}$ & $11(18)$ & $>99$ \\
$\mathrm{LiAlH}_{4}$ & $6(9)$ & 92 \\
\hline
\end{tabular}

a Reaction conditions: $\mathrm{Na}_{3} \mathrm{P}_{3} \mathrm{O}_{9}(1.0 \mathrm{mmol})$, alkali metal hydrides $(3.0 \mathrm{mmol})$ or $\mathrm{NaBH}_{4}(0.75 \mathrm{mmol})$ or $\mathrm{LiAlH}_{4}(0.75 \mathrm{mmol})$, $30 \mathrm{~Hz}, 60 \mathrm{~min} . \quad{ }^{b}$ Determined by ${ }^{31} \mathrm{P}$ NMR spectroscopy. ${ }^{c}$ Based on total $\mathrm{P}$ content. ${ }^{d}$ Parenthesized value includes phosphite in free and phosphorylated forms when phosphorylated phosphites were observed.

Having observed formation of the desired product, we set out to optimize the hydride reagent. An initial survey of hydride sources at stoichiometric loading $(\mathrm{H}: \mathrm{P}=1: 1)$ showed that potassium hydride $(\mathrm{KH})$ gave superior results to other common hydride reagents in regard to conversion of phosphate input and yield of phosphite (Tables 1 and S1). The lower lattice energy of $\mathrm{KH}$ likely contributes to its higher reactivity at the crystal surface. ${ }^{50}$ On account of the higher yields obtained using $\mathrm{KH}$, we chose to use it as the hydride source to continue our study. Use of $\mathrm{KH}$ as the reduc- 
tant also avoided the accumulation of phosphorylated phosphite (isohypophosphate, $\left.\left[\mathrm{O}_{2} \mathrm{HP}-\mathrm{OPO}_{3}\right]^{3-}\right)^{51-54}$ which was formed using other hydride reagents.

During the course of optimization, we also identified hypophosphite $\left(\mathrm{H}_{2} \mathrm{PO}_{2}{ }^{-}\right)$, a species containing phosphorus in the +1 oxidation state, as a product of ball milling. In addition, a phosphorus recovery rate of only $81 \%$ suggested formation of insoluble or gaseous side products (presumably elemental phosphorus and phosphine gas, respectively). These findings pointed toward a non-negligible portion of $\mathrm{Na}_{3} \mathrm{P}_{3} \mathrm{O}_{9}$ undergoing overreduction to yield species in the lower oxidation states. Overreduction consumes hydride equivalents, thereby reducing the yield of phosphite, and also poses a danger to the environment as phosphine gas is known to be highly toxic. ${ }^{1}$

In pursuit of better yield and selectivity of reduction to phosphite, we explored the scope of phosphate sources (Tables 2 and S2). We first tried linear phosphates (pyrophosphate and triphosphate) that are industrially accessible by dehydration of hydrogen or dihydrogen phosphate at $300-900{ }^{\circ} \mathrm{C} .{ }^{1}$ Unlike cyclic phosphates, each polyphosphate molecule $\mathrm{P}_{n} \mathrm{O}_{3 n+1}(n+2)-$ contains only $(n-1) \mathrm{P}$-units that are susceptible to hydride attack, namely, in theory, a polyphosphate with $n \mathrm{P}$-units can only produce $(n-1)$ equivalents of phosphite with one equivalent of orthophosphate as byproduct:

$$
\mathrm{P}_{\mathrm{n}} \mathrm{O}_{3 n+1}{ }^{(\mathrm{n}+2)-}+(\mathrm{n}-1) \mathrm{H}^{-} \stackrel{\&}{\longrightarrow}(\mathrm{n}-1) \mathrm{HPO}_{3}{ }^{2-}+\mathrm{PO}_{4}{ }^{3-}
$$

The reaction of sodium pyrophosphate $\left(\mathrm{Na}_{4} \mathrm{P}_{2} \mathrm{O}_{7}\right)$ with one equivalent of $\mathrm{KH}(\mathrm{H}: \mathrm{P}=1: 2)$ furnished phosphite in $37 \%$ yield within $60 \mathrm{~min}$ of mixing. While elongating the reaction time at the same hydride loading did not improve the yield, an increased yield of phosphite (44\%), which corresponds to $88 \%$ of reactive $\mathrm{P}$-units, was obtained when a higher hydride loading $(\mathrm{H}: \mathrm{P}=1.5: 2)$ was used followed by 90 min of mixing. A similar trend was observed in the reduction of sodium triphosphate $\left(\mathrm{Na}_{5} \mathrm{P}_{3} \mathrm{O}_{10}\right)$ by $\mathrm{KH}$. Mixing $\mathrm{Na}_{5} \mathrm{P}_{3} \mathrm{O}_{10}$ with two equivalents of $\mathrm{KH}(\mathrm{H}: \mathrm{P}=2: 3)$ yielded phosphite in $44 \%$ yield within $60 \mathrm{~min}$, while an increased yield of phosphite (58\%), which corresponds to $87 \%$ of reactive P-units, was obtained at a higher hydride loading ( $\mathrm{H}: \mathrm{P}$ $=1: 1$ ) after $90 \mathrm{~min}$. Only a very low degree of overreduction was observed. Potassium phosphate salts react with $\mathrm{KH}$ in a similar fashion to sodium salts, but more slowly.

Sodium fluorophosphate $\left(\mathrm{Na}_{2} \mathrm{PO}_{3} \mathrm{~F}\right)$ engendered a moderate yield $(47 \%)$ and a notable degree of overreduction. Commercial "sodium hexametaphosphate" or Graham's salt, which is a mixture of cyclic and linear phosphates (Figure S10), afforded a low yield of $29 \%$. Lastly, orthophosphate gave rise to no phosphite, confirming that the presence of phosphoanhydride bonds is key to such reduction reactivity by loss of phosphate as a leaving group. The reactivity of phosphoanhydride bonds predominates biological phosphorylation processes, which involve removal of a terminal $\mathrm{PO}_{3}{ }^{-}$group, such as in processes that consume ATP and produce ADP. ${ }^{55}$

Mechanochemical reduction of $\mathrm{Na}_{4} \mathrm{P}_{2} \mathrm{O}_{7}$ by $\mathrm{KH}$ followed by treatment with deuterium oxide $\left(\mathrm{D}_{2} \mathrm{O}\right)$ resulted in no detected deuterium incorporation in the formed phosphite as determined by ${ }^{31} \mathrm{P}$ NMR spectroscopy, indicating that $\mathrm{KH}$ was the only source of hydrogen atom. This result confirmed phosphorylation of hydride as the exclusive mechanism of phosphite $\mathrm{P}-\mathrm{H}$ bond formation in the current system, ruling out a mechanism of $\mathrm{KH}$ reduction of phosphates to yield $\mathrm{H}$ free low-oxidation-state phosphorus intermediates followed by protonation during aqueous workup.

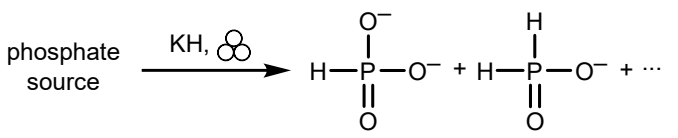

Table 2. Scope of phosphate sources and effects of hydride loading ${ }^{a}$

\begin{tabular}{lcccc}
\hline \multirow{2}{*}{ phosphate } & $\mathrm{H}: \mathrm{P}$ & \multicolumn{2}{c}{ yield $^{b}(\%)$} & recovery $^{c}$ \\
\cline { 3 - 4 } & & $\mathrm{HPO}_{3}{ }^{2-}$ & $\mathrm{H}_{2} \mathrm{PO}_{2}{ }^{-}$ & $(\%)$ \\
\hline $\mathrm{Na}_{3} \mathrm{P}_{3} \mathrm{O}_{9}$ & $1: 1$ & 23 & 2 & 81 \\
$\mathrm{~K}_{4} \mathrm{P}_{2} \mathrm{O}_{7}$ & $1: 2$ & $30[60]^{e}$ & 0 & 98 \\
$\mathrm{Na}_{4} \mathrm{P}_{2} \mathrm{O}_{7}$ & $1: 2$ & $37[74]^{e}$ & 0 & 98 \\
$\mathrm{Na}_{4} \mathrm{P}_{2} \mathrm{O}_{7}{ }^{d}$ & $1.5: 2$ & $44[88]^{e}$ & 0 & 97 \\
$\mathrm{~K}_{5} \mathrm{P}_{3} \mathrm{O}_{10}$ & $2: 3$ & $31[47]^{e}$ & 0 & 98 \\
$\mathrm{Na}_{5} \mathrm{P}_{3} \mathrm{O}_{10}$ & $2: 3$ & $44[66]^{e}$ & trace & 96 \\
$\mathrm{Na}_{5} \mathrm{P}_{3} \mathrm{O}_{10}{ }^{d}$ & $1: 1$ & $58[87]^{e}$ & 0 & 98 \\
$\mathrm{Na}_{2} \mathrm{PO}_{3} \mathrm{~F}$ & $1: 1$ & 47 & 2 & 93 \\
$\mathrm{Graham} \mathrm{Kah}_{3} \mathrm{PO}_{4}$ & $1: 1$ & 29 & 2 & 85 \\
$\mathrm{~K}_{3}$ & $1: 1$ & 0 & 0 & 97 \\
\hline
\end{tabular}

${ }^{a}$ Reaction conditions: $1.0-3.0 \mathrm{mmol} \mathrm{P}, 30 \mathrm{~Hz}, 60 \mathrm{~min} .{ }^{b}$ Based on total $\mathrm{P}$ content; determined by ${ }^{31} \mathrm{P}$ NMR spectroscopy. $\quad{ }^{c}$ Defined as recovery efficiency of total $\mathrm{P}$ content by aqueous extraction, determined by ${ }^{31} \mathrm{P}$ NMR spectroscopy. ${ }^{d} 90 \mathrm{~min} .{ }^{e}$ For polyphosphates $\mathrm{P}_{n} \mathrm{O}_{3 n+1}(n+2)-$, bracketed value of yield is based on $(n-1)$ reactive P-units according to Eq. 4 (two for triphosphate, one for pyrophosphate).

To further improve the yield and alleviate generation of hazardous side products, we set out to seek the chemical origin of overreduction. First, we investigated the stability of phosphite toward hydride. No conversion was observed when sodium phosphite $\left(\mathrm{Na}_{2} \mathrm{HPO}_{3}\right)$ was ball-milled alone or treated with $\mathrm{KH}$ under typical reaction conditions, which rules out disproportionation ${ }^{56,57}$ or hydride attack on phosphite as an overreduction pathway. We then studied the reactions of polyphosphates with various equivalents of hydride (Table S3). Treatment of pyrophosphate with half an equivalent of $\mathrm{KH}(\mathrm{H}: \mathrm{P}=0.5: 2)$ furnished phosphite in a good efficiency ( $74 \%$ based on hydride) without detected overreduction. However, reactions of sodium triphosphate $\left(\mathrm{Na}_{5} \mathrm{P}_{3} \mathrm{O}_{10}\right)$ with substoichiometric $\mathrm{KH}(\mathrm{H}: \mathrm{P}=1: 3)$ resulted in a decreased yield of phosphite $(60 \%$ based on hydride after $60 \mathrm{~min}$, Table S3, entries 7 and 8) and observation of hypophosphite $\left(\mathrm{H}_{2} \mathrm{PO}_{2}{ }^{-}\right)$, an overreduction product not detected when higher hydride loadings were applied (Table S3). Also identified in the reaction were isohypophosphate $\left(\left[\mathrm{O}_{2} \mathrm{HP}-\mathrm{OPO}_{3}\right]^{3-}\right)$ and other phosphorylated phosphites, from which hypophosphite is generated via nucleophilic substitution with hydride (Figure 2(ii),(v),(ix)). These results suggested that, counterintuitively, reducing the amount of hydride employed has led to an increasing tendency for overreduction. A plausible rationale for this is that phosphite, the desired product, can undergo phosphorylation under the reaction conditions (Figure 2(xi)) thereby activating it for a second reduction by hydride (Figure $2(\mathrm{v})$ ). While direct hydride attack at the bridging $\mathrm{P}$-group in triphosphate as a pathway toward phosphorylated phosphite cannot be ruled out at this point, such rise in overreduction is primarily attributed to phosphorylation of generated phosphite. Char- 


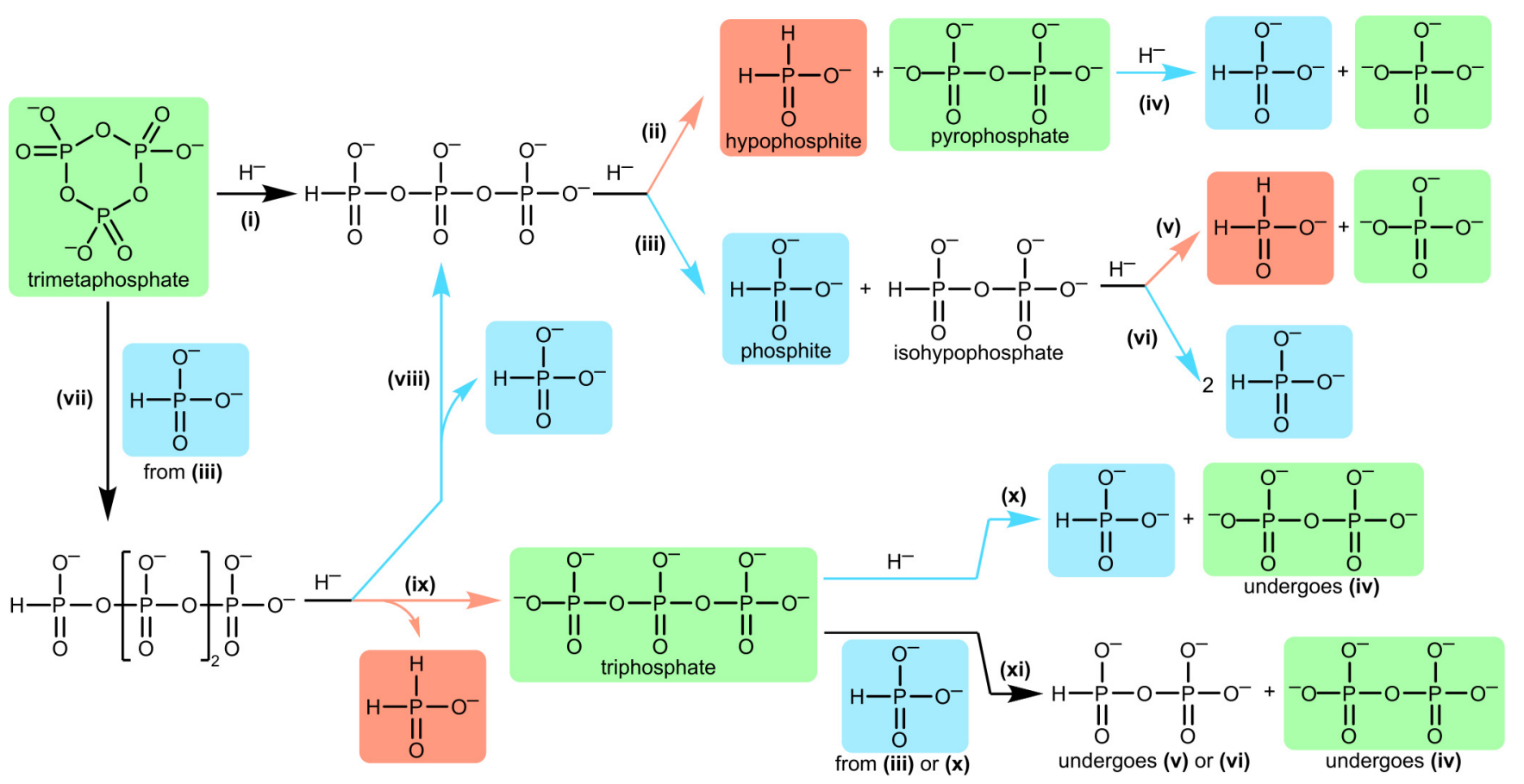

Figure 2. Proposed pathways for phosphite (cyan) and hypophosphite (red) formation from select condensed phosphates (green) applied as phosphate input and/or involved as intermediates.

acterization of the reaction of $\mathrm{Na}_{2} \mathrm{HPO}_{3}$ with $\mathrm{Na}_{5} \mathrm{P}_{3} \mathrm{O}_{10}$ by ${ }^{31} \mathrm{P}$ NMR spectroscopy revealed that phosphite is susceptible to phosphorylation by triphosphate under typical reaction conditions to afford isohypophosphate which may give rise to overreduction. Because this process is in competition with phosphate reduction (Figure 2(vi),(x)), adding excess KH mitigates phosphorylation of phosphite by depleting reactive polyphosphates in the system and thus leads to diminished overreduction. In contrast, pyrophosphate was found to be inefficient at phosphite phosphorylation under these conditions (see SI), which explains the lack of overreduction in its reactions. The observed behavior can be attributed to the diminished leaving group capacity of orthophosphate relative to linear condensed phosphates.

The reactions of sodium trimetaphosphate $\left(\mathrm{Na}_{3} \mathrm{P}_{3} \mathrm{O}_{9}\right)$ with $\mathrm{KH}$ displayed a higher degree of overreduction (with up to $7 \%$ yield of hypophosphite; Table S3, entries 1-6) compared to the reactions of pyrophosphate and triphosphate. When $\mathrm{Na}_{3} \mathrm{P}_{3} \mathrm{O}_{9}$ was treated with substoichiometric $\mathrm{KH}(\mathrm{H}: \mathrm{P}=1: 3)$, phosphorylated phosphites of various chain lengths were the major reduction products instead of free phosphite, pointing toward a mechanism of hydride phosphorylation through ring opening followed by stepwise cleavage of terminal phosphates (Figure 2(i),(iii)). The ring opening reactivity of trimetaphosphate was further demonstrated by the facile mechanochemical reaction between $\mathrm{Na}_{3} \mathrm{P}_{3} \mathrm{O}_{9}$ and $\mathrm{Na}_{2} \mathrm{HPO}_{3}$, affording phosphorylated terminal phosphites of various chain lengths (Figure 2(vii)), which were assigned based on a combination of 1D- and 2D${ }^{31} \mathrm{P}$ NMR spectroscopic techniques (see SI). These results suggest that the ring-opening reactivity of trimetaphosphate provides additional pathways to form phosphorylated phosphites and thus significantly increases the degree of overreduction.

Despite having only one reactive P-unit per molecule, sodium pyrophosphate is a useful phosphate source due to its highly selective and efficient conversion to phosphite.
Therefore, we carried out phosphite isolation studies using $\mathrm{Na}_{4} \mathrm{P}_{2} \mathrm{O}_{7}$ as starting material. Isolation of phosphite from phosphates in the crude mixture was achieved through precipitating orthophosphate as struvite $\left(\mathrm{NH}_{4} \mathrm{MgPO}_{4} \cdot 6 \mathrm{H}_{2} \mathrm{O}\right)$, taking advantage of the low solubility of this mineral. ${ }^{58}$ This method led to a $34 \%$ isolated yield of phosphite $(67 \%$ based on reactive $\mathrm{P}$ ) in the form of a barium phosphite salt $\mathrm{BaHPO}_{3} \cdot \mathrm{H}_{2} \mathrm{O}$ (see SI). Phosphorous acid solutions can be prepared by treatment of the barium phosphite salt with sulfuric acid, ${ }^{59}$ and protocols for separation of phosphorous acid from phosphoric acid on an industrial scale are well established. ${ }^{60-63}$

In biological systems, long-chain polyphosphate (polyP) is involved in ATP synthesis catalyzed by polyP kinases in which polyP is the source of a third $\mathrm{PO}_{3}{ }^{-}$group leading to ATP. ${ }^{64,65}$ Inspired by the biochemical reactivity of polyP, we turned our attention to the application of bioproduced polyP as a source of $\mathrm{PO}_{3}{ }^{-}$. A recent protocol of polyP accumulation using Saccharomyces cerevisiae (baker's yeast) followed by isolation allowed us to obtain bioproduced polyP (bio-polyP, Figure 3) in multigram quantities. ${ }^{66,67}$ The composition and structure of the isolated bio-polyP was analyzed by ${ }^{31} \mathrm{P}$ NMR spectroscopy in conjunction with several elemental analytical methods. Linear phosphates (with $\mathrm{Na}^{+}$, $\mathrm{Mg}^{2+}, \mathrm{K}^{+}$, and $\mathrm{Ca}^{2+}$ as counterions) constitute $77.8 \mathrm{wt} . \%$ of bio-polyP with an average degree of polymerization of 37 , whereas residual orthophosphate and trimetaphosphate are $<1.5$ wt. $\%$. The measured metal composition and average chain length of the isolated bio-polyP are similar to those of intracellular polyphosphates in bacteria in EBPR systems. ${ }^{68,69}$ Major impurities include residual organic substances (protein and nucleic acid), water, and $\mathrm{NaCl}$.

Mechanochemical reduction of bio-polyP with excess $\mathrm{KH}$ ( $\mathrm{H}: \mathrm{P}=2.0: 1)$ on a 0.2 g-scale afforded phosphite in $28 \%$ yield, far lower than the theoretical yield (97\% P-units are reactive). Instead, a high yield of orthophosphate (67\%) was observed and is mainly attributed to the interference from 


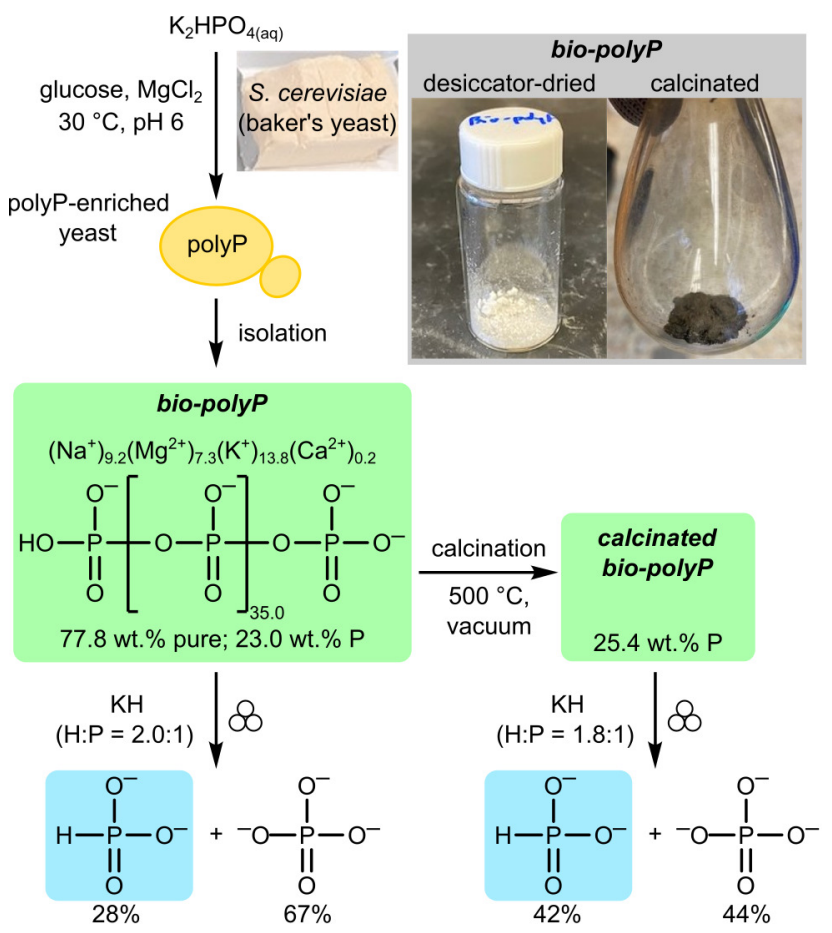

Figure 3. Biotechnological production, properties, and mechanochemical reactivity of bio-polyP. Inset: photos of a bio-polyP sample dried in a desiccator at $25{ }^{\circ} \mathrm{C}$ (left) and a bio-polyP sample after calcination (right).

oxygen-containing impurities including water and residual organic mass.

Preliminary experiments revealed that the affecting impurities can be partially removed through vacuum calcination. While bio-polyP is labile upon heating under air at $120{ }^{\circ} \mathrm{C}$ as well as under ball milling conditions, affording orthophosphate and short-chain polyphosphates (see SI), calcination of bio-polyP at $500{ }^{\circ} \mathrm{C}$ under reduced pressure pyrolyzes organic impurities and removes the water content. The resulting dark material (Figure 3 inset) cannot be effectively extracted with water, but a ${ }^{31} \mathrm{P}$ NMR spectrum of its aqueous extract still confirmed long-chain polyphosphate as the predominant form of P. Calcinated bio-polyP engendered an increased phosphite yield of $42 \%$.

In conclusion, we have demonstrated that phosphite can be accessed via direct reduction of polyphosphates by simple metal hydrides, using mechanochemical methods. Unlike the thermal process, this direct process bypasses the hazardous intermediate white phosphorus, and ostensibly does not traverse lower phosphorus oxidation states than +3 . Optimization of reaction conditions revealed that high phosphite production yields and good selectivity can be achieved when employing linear phosphates as phosphate sources with $\mathrm{KH}$ as the hydride source. The optimized protocol employing pyrophosphate, which contains only the poor leaving group orthophosphate, gives high selectivity for the targeted $\mathrm{P}(\mathrm{V}) \rightarrow \mathrm{P}(\mathrm{III})$ reduction. Mechanistic studies revealed that (poly)phosphorylated phosphite species that are generated through either ring opening of cyclic phosphates by hydride or phosphorylation of formed phosphite are key intermediates in the overreduction pathways observed when not using pyrophosphate as the $\mathrm{P}$ source. By using bioproduced polyphosphate from baker's yeast, we demonstrated that polyphosphates recovered from microorganisms could be promising starting materials for sustainable production of phosphite, while certain impurities may be detrimental to the efficiency of production. With this case study we lay down an idealized framework for generating an industrially useful P(III) chemical that bypasses toxic and high-energy intermediates and presents an opportunity to move toward a 'closed-loop' phosphorus industry.

\section{Acknowledgments}

The corresponding author had the idea to conduct the title reaction following a pre-pandemic visit to the laboratory of T. Friščić at McGill University. Funding for this research was provided by the Abdul Latif Jameel Water and Food Systems Lab (J-WAFS) at MIT, and by the MIT Indonesia Seed Fund. We acknowledge M. Dincă (MIT) for generously providing access to the ball mill, E.D. Badding, G. Namkoong, and D.L.M. Suess (MIT) for generously providing access to the incubator and centrifuge, and B.G. Fiss (McGill) and A.T. Radosevich (MIT) for thoughtful discussions and suggestions.

\section{Competing Interests}

The authors declare no competing interests.

\section{Supporting Information}

Experimental details of mechanochemical reactions, characterization data, and protocol for accumulation and isolation of bio-polyP from baker's yeast are provided in the Supporting Information document.

\section{References}

(1) Bettermann, G.; Krause, W.; Riess, G.; Hofmann, T. Ullmann's Encyclopedia of Industrial Chemistry, Vol. 27; Wiley-VCH, Weinheim, 2000

(2) Asl, H. Y.; Choudhury, A. Phosphite as Polyanion-Based Cathode for Li-Ion Battery: Synthesis, Structure, and Electrochemistry of $\mathrm{LiFe}\left(\mathrm{HPO}_{3}\right)_{2}$. Inorg. Chem. 2015, 54, 6566-6572.

(3) Asl, H. Y.; Ghosh, K.; Meza, M. P. V.; Choudhury, A $\mathrm{Li}_{3} \mathrm{Fe}_{2}\left(\mathrm{HPO}_{3}\right)_{3} \mathrm{Cl}$ : an electroactive iron phosphite as a new polyanionic cathode material for Li-ion battery. J. Mater. Chem. A 2015, 3, 7488-7497.

(4) Ma, Z.; Lander, L.; Nishimura, S.-i.; Okubo, M.; Yamada, A $\mathrm{HPO}_{3}^{2-}$ as a building unit for sodium-ion battery cathodes: 3.1 $\mathrm{V}$ operation of $\mathrm{Na}_{2-x} \mathrm{Fe}\left(\mathrm{HPO}_{3}\right)_{2}(0<x<1)$. Chem. Commun 2019, 55, 14155-14157.

(5) Dill, G. M.; Sammons, R. D.; Feng, P. C. C.; Kohn, F. Kretzmer, K.; Mehrsheikh, A.; Bleeke, M.; Honegger, J. L.; Farmer, D.; Wright, D.; Haupfear, E. A. Glyphosate Resistance in Crops and Weeds; John Wiley \& Sons, Ltd, 2010; Chapter 1 pp 1-33.

(6) Coudray, L.; Montchamp, J.-L. Recent Developments in the Addition of Phosphinylidene-Containing Compounds to Unactivated Unsaturated Hydrocarbons: Phosphorus-Carbon Bond Formation by Hydrophosphinylation and Related Processes. Eur. J. Org. Chem. 2008, 2008, 3601-3613.

(7) Xu, Q.; Han, L.-B. Metal-catalyzed additions of $\mathrm{H}-\mathrm{P}(\mathrm{O})$ bonds to carbon-carbon unsaturated bonds. J. Organomet. Chem. 2011, 696, 130-140.

(8) Zoń, J.; Garczarek, P.; Białek, M. Metal Phosphonate Chemistry: From Synthesis to Applications; The Royal Society of Chemistry, 2012; pp 170-191

(9) Sobkowski, M.; Kraszewski, A.; Stawinski, J. In Phosphorus Chemistry II: Synthetic Methods; Montchamp, J.-L., Ed.; Springer International Publishing: Cham, 2015; pp 179-216.

(10) Rodriguez-Ruiz, V.; Carlino, R.; Bezzenine-Lafollée, S.; Gil, R.; Prim, D.; Schulz, E.; Hannedouche, J. Recent developments in alkene hydro-functionalisation promoted by homogeneous catalysts based on earth abundant elements: formation of C-N, C-O and C-P bond. Dalton Trans. 2015, 44, 12029-12059. 
(11) Sevrain, C. M.; Berchel, M.; Couthon, H.; Jaffrès, P.-A. Phosphonic acid: preparation and applications. Beilstein J. Org. Chem. 2017, 13, 2186-2213.

(12) Huke, C. D.; Kays, D. L. Advances in Organometallic Chemistry; Elsevier, 2021; Vol. 75; pp 1-54

(13) Achary, V. M. M.; Ram, B.; Manna, M.; Datta, D.; Bhatt, A.; Reddy, M. K.; Agrawal, P. K. Phosphite: a novel P fertilizer for weed management and pathogen control. Plant Biotechnol. J. 2017, 15, 1493-1508.

(14) López-Arredondo, D. L.; Herrera-Estrella, L. Engineering phosphorus metabolism in plants to produce a dual fertilization and weed control system. Nat. Biotechnol. 2012, 30, 889-893.

(15) Pandeya, D.; López-Arredondo, D. L.; Janga, M. R.; Campbell, L. M.; Estrella-Hernández, P.; Bagavathiannan, M. V.; Herrera-Estrella, L.; Rathore, K. S. Selective fertilization with phosphite allows unhindered growth of cotton plants expressing the ptxD gene while suppressing weeds. Proc. Natl. Acad. Sci. U. S. A. 2018, 115, E6946-E6955.

(16) Herschy, B.; Chang, S. J.; Blake, R.; Lepland, A.; AbbottLyon, H.; Sampson, J.; Atlas, Z.; Kee, T. P.; Pasek, M. A. Archean phosphorus liberation induced by iron redox geochemistry. Nat. Commun. 2018, 9, 1346 .

(17) Diskowski, H.; Hofmann, T. Ullmann's Encyclopedia of Industrial Chemistry, Vol. 26; Wiley-VCH, Weinheim, 2000.

(18) Ohtake, H.; Tsuneda, S. Phosphorus recovery and recycling; Springer, 2019

(19) Cordell, D.; Drangert, J.-O.; White, S. The story of phosphorus: global food security and food for thought. Glob. Environ. Change 2009, 19, 292-305.

(20) Cordell, D.; White, S. Peak phosphorus: clarifying the key issues of a vigorous debate about long-term phosphorus security. Sustainability 2011, 3, 2027-2049.

(21) Dawson, C. J.; Hilton, J. Fertiliser availability in a resourcelimited world: Production and recycling of nitrogen and phosphorus. Food Policy 2011, 36, S14-S22.

(22) Werner, W. Ullmann's Encyclopedia of Industrial Chemistry, Vol. 14; Wiley-VCH, Weinheim, 2009

(23) Akbari, A.; Wang, Z; He, P.; Wang, D ; Lee, J.; Han, I.; Li, G. $\mathrm{Gu}, \mathrm{A}$. Z. Unrevealed roles of polyphosphate-accumulating microorganisms. Microb. Biotechnol. 2021, 14, 82-87.

(24) Vučić, V.; Müller, S. New developments in biological phosphorus accessibility and recovery approaches from soil and waste streams. Eng. Life Sci. 2021, 21, 77-86.

(25) Izadi, P.; Izadi, P.; Eldyasti, A. Design, operation and technology configurations for enhanced biological phosphorus removal (EBPR) process: a review. Rev. Environ. Sci. Biotechnol. 2020 19, 561-593.

(26) Hirota, R.; Kuroda, A.; Kato, J.; Ohtake, H. Bacterial phosphate metabolism and its application to phosphorus recovery and industrial bioprocesses. J. Biosci. Bioeng. 2010, 109, 423432

(27) Kashihara, H.; Kang, B. M.; Omasa, T.; Honda, K.; Sameshima, Y.; Kuroda, A.; Ohtake, H. Electron microscopic analysis of heat-induced leakage of polyphosphate from a phoU mutant of Escherichia coli. Biosci. Biotechnol. Biochem. 2010, 74, 865-868.

(28) Geeson, M. B.; Cummins, C. C. Phosphoric acid as a precursor to chemicals traditionally synthesized from white phosphorus. Science 2018, 359, 1383-1385.

(29) Swager, T. M.; Peeks, M. D. Trichlorosilane Paves the Way from Phosphoric Acid to Phosphorous Molecules. Synfacts 2018, 14 592.

(30) Slootweg, J. C. Sustainable Phosphorus Chemistry: A Silylphosphide Synthon for the Generation of Value-Added Phosphorus Chemicals. Angew. Chem., Int. Ed. 2018, 57, 6386-6388.

(31) Protasiewicz, J. D. From rock-stable to reactive phosphorus. Science 2018, 359, 1333 .

(32) Geeson, M. B.; Ríos, P.; Transue, W. J.; Cummins, C. C. Orthophosphate and Sulfate Utilization for $\mathrm{C}-\mathrm{E}(\mathrm{E}=\mathrm{P}, \mathrm{S})$ Bond Formation via Trichlorosilyl Phosphide and Sulfide Anions. J. Am. Chem. Soc. 2019, 141, 6375-6384

(33) Geeson, M. B.; Cummins, C. C. Let's Make White Phosphorus Obsolete. ACS Cent. Sci. 2020, 6, 848-860.

(34) Jupp, A. R.; Beijer, S.; Narain, G. C.; Schipper, W.; Slootweg, J. C. Phosphorus recovery and recycling - closing the loop. Chem. Soc. Rev. 2021, 50, 87-101.

(35) Sordakis, K.; Tang, C.; Vogt, L. K.; Junge, H.; Dyson, P. J. Beller, M.; Laurenczy, G. Homogeneous Catalysis for Sustainable Hydrogen Storage in Formic Acid and Alcohols. Chem. Rev. 2018, 118, 372-433.

(36) Wang, W.-H.; Himeda, Y.; Muckerman, J. T.; Manbeck, G. F.; Fujita, E. $\mathrm{CO}_{2}$ Hydrogenation to Formate and Methanol as an Alternative to Photo- and Electrochemical $\mathrm{CO}_{2}$ Reduction. Chem. Rev. 2015, 115, 12936-12973.

(37) Schrödter, K.; Bettermann, G.; Staffel, T.; Wahl, F.; Klein, T. Hofmann, T. Ullmann's Encyclopedia of Industrial Chemistry, Vol. 26; Wiley-VCH, Weinheim, 2008

(38) Pham Minh, D.; Ramaroson, J.; Nzihou, A.; Sharrock, P. Onestep synthesis of sodium trimetaphosphate $\left(\mathrm{Na}_{3} \mathrm{P}_{3} \mathrm{O}_{9}\right)$ from sodium chloride and orthophosphoric acid. Ind. Eng. Chem. Res. 2012, 51, 3851-3854.

(39) Andersen, J.; Mack, J. Mechanochemistry and organic synthesis from mystical to practical. Green Chem. 2018, 20, 1435-1443.

(40) Do, J.-L.; Friščić, T. Mechanochemistry: A Force of Synthesis.
ACS Cent. Sci. 2017, 3, 13-19.

(41) James, S. L et al. Mechanochemistry: opportunities for new and cleaner synthesis. Chem. Soc. Rev. 2012, 41, 413-447.

(42) Tan, D.; García, F. Main group mechanochemistry: from curiosity to established protocols. Chem. Soc. Rev. 2019, 48, 2274 2292.

(43) Tan, D.; Friščić, T. Mechanochemistry for Organic Chemists: An Update. Eur. J. Org. Chem. 2018, 18-33.

(44) Friščić, T.; Mottillo, C.; Titi, H. M. Mechanochemistry for Synthesis. Angew. Chem., Int. Ed. 2020, 59, 1018-1029.

(45) Ardila-Fierro, K. J.; Hernández, J. G. Sustainability Assessment of Mechanochemistry by Using the Twelve Principles of Green Chemistry. ChemSusChem 2021, 14, 2145-2162.

(46) Lukin, S.; Užarević, K.; Halasz, I. Raman spectroscopy for realtime and in situ monitoring of mechanochemical milling reactions. Nat. Protoc. 2021, 16, 3492-3521.

(47) Ardila-Fierro, K. J.; Lukin, S.; Etter, M.; Užarević, K.; Halasz, I.; Bolm, C.; Hernández, J. G. Direct Visualization of a Mechanochemically Induced Molecular Rearrangement. Angew. Chem., Int. Ed. 2020, 59, 13458-13462.

(48) Shi, F.; Shi, J.; Li, Y. Mechanochemical Phosphorylation and Solubilisation of $\beta$-D-Glucan from Yeast Saccharomyces cerevisiae and Its Biological Activities. PLoS ONE 2014, 9 , e103494.

(49) Fiss, B. G.; Hatherly, L.; Stein, R. S.; Friščić, T.; Moores, A. Mechanochemical Phosphorylation of Polymers and Synthesis of Flame-Retardant Cellulose Nanocrystals. ACS Sustainable Chem. Eng. 2019, 7, 7951-7959.

(50) Brown, C. A. Saline hydrides and superbases in organic reactions. VII. Potassium hydride, highly active new hydride reagent. Reactivity, applications, and techniques in organic and organometallic reactions. J. Org. Chem. 1974, 39, 3913-3918.

(51) Carroll, R. L.; Mesmer, R. E. Isohypophosphate: kinetics of the hydrolysis and potentiometric and nuclear magnetic resonance studies on the acidity and complexing. Inorg. Chem. 1967, 6 $1137-1142$

(52) Yoza, N.; Tokushige, N.; Nakazato, T.; Takehara, K.; Ide, Y.; Baba, Y. Oxidative conversion of diphosphonate to diphosphate and isohypophosphate by hydrogen peroxide. Chem. Lett. 1990, 19, 1487-1490.

(53) Yoza, N.; Okamatsu, M.; Tokushige, N.; Miyajima, T.; Baba, Y. Nucleophilic substitution reactions between diphosphonate and orthophosphate characterized by high-performance liquid chromatography and ${ }^{31} \mathrm{P}$ NMR spectroscopy. Bull. Chem. Soc. Jpn. 1991, 64, 16-20

(54) Kee, T. P.; Bryant, D. E.; Herschy, B.; Marriott, K. E.; Cosgrove, N. E.; Pasek, M. A.; Atlas, Z. D.; Cousins, C. R. Phosphate activation via reduced oxidation state phosphorus $(\mathrm{P})$. Mild routes to condensed-P energy currency molecules. Life 2013, 3, 386-402.

(55) Knowles, J. R. Enzyme-Catalyzed Phosphoryl Transfer Reactions. Annu. Rev. Biochem. 1980, 49, 877-919.

(56) Gokhale, S. D.; Jolly, W. L.; Thomas, S.; Britton, D. Inorganic Syntheses; John Wiley \& Sons, Ltd, 1967; Chapter 5, pp 56-58.

(57) Liu, D.; Li, X.; Wei, L.; Zhang, T.; Wang, A.; Liu, C.; Prins, R. Disproportionation of hypophosphite and phosphite. Dalton Trans. 2017, 46, 6366-6378.

(58) Doyle, J. D.; Parsons, S. A. Struvite formation, control and recovery. Water Res. 2002, 36, 3925-3940.

(59) Platova, E. V.; Batyeva, E. S.; Kursheva, L. I.; Sinyashin, O. G. Synthesis of phosphorous acid and its derivatives based on the reaction of elemental phosphorus $\left(\mathrm{P}_{4}\right)$ and aqueous solution of choline in the presence of the hydroxides of earth alkali metals. Heteroat. Chem. 2008, 19, 517-519.

(60) Malowan, J. E. Process for the purification of phosphorous acid 1958; US Patent 2,857,246.

(61) Kovacs, W. L.; Pflaumer, P. F.; Whyte, D. D. Separation of phosphorous acid from mixtures of phosphorous acid and phosphoric acid by amine extraction. 1972; US Patent 3,632,311.

(62) Kovacs, W. L. Separation of phosphorus acid from mixtures of phosphorus acid and phosphoric acid by crystallization. 1972 US Patent 3,679,374.

63) Kovacs, W. Pflaumer, P. Whyte, D. Separation of phosphorous and phosphoric acids by alcoholic countercurrent extraction. 1973; US Patent 3,769,384.

(64) Achbergerova, L.; Nahalka, J. Polyphosphate - an ancient energy source and active metabolic regulator. Microb. Cell Fact. 2011 10,63 .

(65) Rao, N. N.; Gómez-García, M. R.; Kornberg, A. Inorganic Polyphosphate: Essential for Growth and Survival. Annu. Rev. Biochem. 2009, 78, 605-647.

(66) Christ, J. J.; Blank, L. M. Saccharomyces cerevisiae containing $28 \%$ polyphosphate and production of a polyphosphate-rich yeast extract thereof. FEMS Yeast Res. 2019, 19, foz011.

(67) Christ, J. J.; Smith, S. A.; Willbold, S.; Morrissey, J. H. Blank, L. M. Biotechnological synthesis of water-soluble foodgrade polyphosphate with Saccharomyces cerevisiae. Biotechnol. Bioeng. 2020, 117, 2089-2099.

(68) Li, Y.; Rahman, S. M.; Li, G.; Fowle, W.; Nielsen, P. H. $\mathrm{Gu}, \mathrm{A}$. Z. The Composition and Implications of PolyphosphateMetal in Enhanced Biological Phosphorus Removal Systems. Environ. Sci. Technol. 2019, 53, 1536-1544.

(69) Wang, D. et al. Intracellular polyphosphate length characterization in polyphosphate accumulating microorganisms (PAOs): 
Implications in PAO phenotypic diversity and enhanced biolog-

ical phosphorus removal performance. Water Res. 2021, 206, 117726 . 


\section{Graphical TOC Entry}

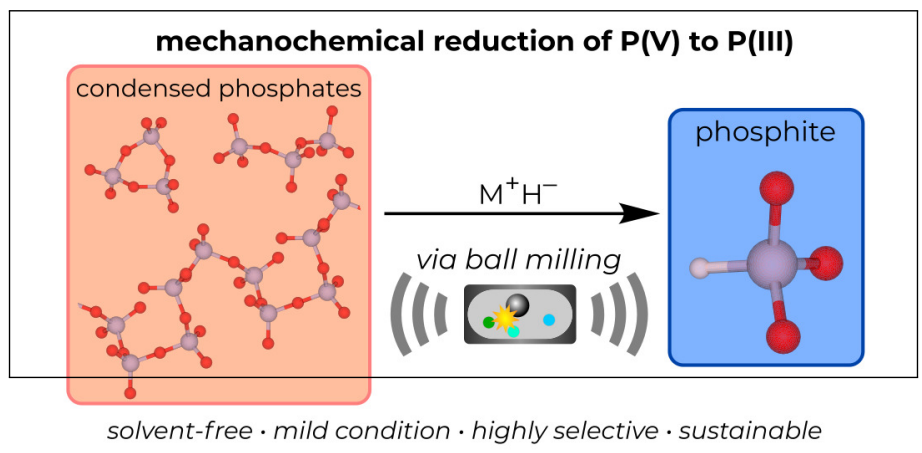

